\title{
Regulating invasive species with different life history
}

\author{
Katarina Elofsson • Ing-Marie Gren
}

Published online: 29 May 2014

(C) The Author(s) 2014. This article is published with open access at Springerlink.com

\begin{abstract}
Invasive species often cause economic damage due to their impact on economically valuable resident species. We study optimal regulation in terms of simultaneous control and adaptation when the purpose is to manage an invasive species which competes for scarce resources with a resident species. The optimal policy includes both subsidies for control of an invasive species with zero commercial value, and harvesting taxes on the resident species which are adjusted in the presence of an invasion. A numerical age-structured optimization model is used to analyze the role of species' life history, i.e. the degree of evolutionary specialization in survival or reproduction, for the choice of strategy and the associated economic instruments. Results show that, irrespective of life history, both policies are implemented in efficient solutions, but subsidies for controlling the invader are used to a larger extent when it is possible to target specific age classes of the invader. If a resident species is harvested nonselectively, the optimal subsidy for control of the invader is lower, and if the invader is specialized in survival the control subsidy mirrors the resident species harvest cycle.
\end{abstract}

Keywords Invasive species - Life history - Control subsidy · Harvesting tax · Adaptation

JEL Classification Q28 - Q57

\section{Introduction}

Invasive species, i.e. species that are introduced into a natural environment where they are not normally found, can give rise to large economic damage due to their impact

K. Elofsson $(\varangle) \cdot$ I.-M. Gren

Department of Economics, Swedish University of Agricultural Sciences,

Box 7013, 75007 Uppsala, Sweden

e-mail: katarina.elofsson@slu.se 
on native species, wildlife habitats, forest and agriculture productivity, and recreation (Pimentel et al. 2005; Colautti et al. 2006; Gren et al. 2009). Estimates of damage costs indicate that they can correspond to 5-10\% of GDP (Gren et al. 2009). In principle, there are three ways to reduce the damage of invasive species; prevention, control and adaptation. Prevention efforts inhibit the entrance of species into new regions, control measures directly regulate the size and dispersal of the invader population, and adaptation measures reduce the damage caused by the invader through adjustments of ongoing economic activities at the site such as, e.g., changes in the management of wild native species, and in agricultural and forestry production which reduce the risk of damages from an invasion. ${ }^{1}$

Existing international agreements of relevance for the management of invasive species concentrate on policies for prevention of unwanted introductions, whereas little guidance is provided regarding the policies for control or adaptation (Secretariat of the Convention on Biological Diversity 2001). However, prevention measures sometimes fail to stop the introduction of an invader. The subsequent establishment and growth, and the associated economic consequences, is then determined by the interaction with resident species already present in the habitat. One example is the introduction of the round goby (Neogobius melanostomus) in the Baltic Sea in the late 1980s. The round goby has become the dominant demersal fish species in shallow water and competes for food with the commercially valuable native flounder (Platichthys flesus) (Karlson et al. 2007). Another example is ringed (Phoca hispida) and grey seal (Halichoerus grypus), where populations in the Baltic Sea have recently recovered from very low levels caused by, first, extensive hunting in the last century and, later, toxic pollutants (Österblom et al. 2007). Seals are highly piscivorous and therefore compete for food with the commercially valuable cod (Harvey et al. 2003). Even though the seals' fish consumption is negligible in relation to commercial cod catches on the larger Balticwide scale, the consumed fish biomass can be of the same magnitude as fishery catches, or even larger, at the regional scale (Lundström et al. 2012). The interaction between a resident and invasive species suggests that the optimal choice of policy instruments should be considered in a multispecies framework (Fleming and Alexander 2003). This can be of particular interest for efficient management of invasive species. When the resident and invasive species compete the invader can be limited, not only by direct control of that species, but also by reducing harvests of the resident species in order to increase competition for the common food resource and, thereby, crowd out the invader. Such control of and adaptation to biological invasions has, to the best of our knowledge, not been analyzed in the earlier literature, which is further described in Sect. 2.

There is an increasing role of anthropogenic introductions of invasive species, implying that the ability of the invasive species to compete with resident species and get established in the new habitat is successively becoming more important compared

\footnotetext{
1 There are various definitions of adaptation, e.g. Perrings (2005) defines adaptation as actions that reduce the impact of introduction, establishment or spread of an invader without changing the likelihood that it will occur. Finnoff et al. (2005) exemplifies firm level adaptation by a power plant choosing to operate longer hours or burn more fuel than otherwise in order to compensate for coolant systems being clogged by zebra mussels.
} 
to the biological dispersal ability of potential invaders (MacArthur and Wilson 1967; Hulme 2009). This strengthens the need to fit policies to the progress stage of the invasion, e.g., by control and adaptation being applied when the effect is particularly high. The effectiveness of control and adaptation at a particular point in time depends on characteristics of invading and resident species, and on the degree of establishment of the invader. The purpose of this study is therefore to analyze the role of life history, i.e. the degree of evolutionary specialization in survival or reproduction, of invasive and commercial resident species for the optimal choice of strategy and the associated economic instruments. We use a numerical two-species, age-structured model to analyze policies for biological invasions. This discrete-time dynamic model allows for analysis of how policies for control and adaptation depend on the species' life history, i.e. their degree of specialization in reproduction or survival, when the invasive and resident species compete for scarce resources. The model is relevant for iteroparous species, i.e. species which are reproducing repeatedly over their life time, marine or land-living, which demand the same scarce resource, and where the resident species is harvested with a selective or non-selective method. We investigate the economic tradeoff between control and adaptation, and the associated control subsidy and adjustment of the optimal harvesting tax. This is done with an aim to examine how these policy instruments depend on species' life history and on the technology for harvest of the resident species.

Multi-species age-structured models are mostly used in analysis of fishery management (Bertignac et al. 2000; Nieminen et al. 2012), where they are motivated by their high biological relevance and the importance of species age for management decisions taken. To the best of our knowledge, this modeling approach has only been applied to invasive species management by Elofsson et al. (2012), who analyze efficiency properties of adaptation measures in a two-population setting, but do not include control measures or analyze policy instruments. In our view, this paper contributes to the literature on policies for control of and adaptation to invasive species by analysis of how the trade-off between control and adaptation is affected by; (i) eco-system interdependences between invading and resident species, (ii) invader age at the time of arrival, and (iii) species' life history, i.e. survival and reproduction characteristics. It also contributes through the analysis of the role of species' life history and harvesting technology for the joint choice of harvesting tax and control subsidy in the presence of an invasion.

The paper is organized as follows; a brief literature review is provided in Sect. 2, the bio-economic model is presented in Sects. 3 and 4, and data for the empirical model are given in Sect. 5. Next, the results are presented in Sect. 6 and the paper ends with a discussion and conclusions in Sect. 7.

\section{Brief literature review}

Economics of invasive species is a relatively recent but rapidly growing body of literature in environmental economics. Starting in early 1990s the main focus was on estimating damage costs of invasive species, such as the OTA (1993) study of 79 noxious species in US. Surveys of such studies are found in Born et al. (2005) and Olson 
(2006). A majority of the later studies raise the question on when in the invasion chain - entrance, establishment, dispersal, and creation of damage - to act against an invader (see review in Gren 2008). The optimal balance between prevention and control for a single invasive species is then shown to depend on its characteristics such as, e.g., propagule pressure, growth rate, and dispersal (Leung et al. 2002; Olson and Roy 2005; Jayasuriya et al. 2011), and the manager's attitude and behavior, including time until discovery (Kim et al. 2006), and the manager's risk aversion and learning options (Saphores and Shogren 2005; Finnoff et al. 2007). Most of these studies focus on the invader, and not on its interaction with the resident species. Knowler and Barbier (2000) and Knowler et al. (2001) provide exceptions by investigating the interaction between the invasive comb jelly and the resident anchovy in the Black Sea. However, they only consider a unilateral impact of an invader on a resident species, and not the mutual interdependence implied by competition for food or space which is in the focus of this study. Barbier (2001, 2007) outlines the importance of different types of interaction between resident and invasive species, but does not investigate the role of species life history characteristics for this interaction. Another common feature of most studies is the lack of age-structured models. The only studies with such models were Hastings et al. (2006) and Elofsson et al. (2012). Hastings et al. (2006) show the prioritization of removal of a single age or stage class of the invasive saltmarsh cordgrass in the Washington state in the US, and Elofsson et al. (2012) point to the need of considering harvesting selectivity when adjusting harvests of a resident species in order to limit the expansion of an invader population.

Only a few studies had the explicit aim of analyzing and suggesting policies for efficient management of invasive species, which were mainly directed towards international trade in order to inhibit entrance of invaders, such as a tax on imports or the design of inspection of cargos and vessels (e.g. Knowler and Barbier 2005; Batabyal 2007; Barbier et al. 2013). Other studies investigated the potential of a market for trading in invasion risks (Horan and Lupi 2005), and Jetter et al. (2003) who investigated control subsidies for an invasive plant species. No study examined the optimal combination of policies on both the invader and the resident species. On the other hand, the use of policy instruments for sustainable management of commercially harvested species, such as harvesting taxes and harvest quotas is well researched in fishery economics (Clark 1990; Weitzman 2002; Jensen and Vestergaard 2002; Hannesson and Kennedy 2005), but the appropriate adjustment of such instruments in the presence of a biological invasion has so far not been investigated.

\section{Bio-economic model}

In order to analyze the role of species' life history, we classify species into two types, $A$ and $B$, corresponding to so called iteroparous species of type I and III, respectively. The classification is based on the observation that species have a limited amount of energy available, which must be allocated between fecundity and survival, thereby defining their life history strategy. The type $A$ life history is found among species that spend large efforts to protect their relatively few offspring, thereby increasing the probability of survival of the young, such as mammals (Deevey 1947; Polis and Farley 
1980). The type $B$ life history is found among species that produce high numbers of young at a cost of low juvenile survival. This type of life history is common among fish, insects, marine invertebrates, and plants. A type $A$ species has a high survival rate as a juvenile, but the survival rate falls as age increases and reproduction is low for all mature age classes. Type $B$ species have a low juvenile survival, but the survival rate increases with age. Reproduction is high once it has reached maturity (Lack 1954; Williams 1966; Pianka and Parker 1975).

Following Elofsson et al. (2012), we assume there are two species populations, one resident and one invader, each associated with a life history $j$, with $j=A, B$. A stock transition relationship describes the development of the populations over time. The number of individuals in cohort $a+1$ of the resident species, $R_{t+1}^{a+1, j}$, counted before the reproductive season, is defined by:

$$
\begin{aligned}
R_{t+1}^{a+1, j}= & R_{t}^{a j} s^{a+1, j} e^{-\sum_{a}\left(\beta^{a j} R_{t}^{a j}+\mu^{a j} I_{t}^{a j}\right)} \\
& -H_{t+1}^{a+1, j} \quad \forall j=A, B, \quad \forall a=0,1, \ldots, \bar{a}
\end{aligned}
$$

where

$$
\begin{aligned}
& H_{t}^{a j}=0 \quad \forall a<\underline{h}, \\
& H_{t}^{a j} \geq 0 \quad \forall \underline{h} \leq a \leq \bar{a} \text { and } \\
& R_{0}^{a j}=\bar{R}_{0}^{a j}
\end{aligned}
$$

where $R_{t}^{a j}$ and $I_{t}^{a j}$ denote the number of individuals of resident and invader species, respectively, belonging to cohort $a$ at time $t$ and $H_{t}^{a j}$ is the harvest of age class $a$ of the resident species at time $t$. We thereby assume that in each time period, harvest occurs before natural mortality. The term $s^{a+1, j}$ denotes the fraction of individuals of cohort $a$ surviving until the following year in the absence of competition for limiting resources, such as food or space, within and between species. However, in the presence of competition, the number of individuals of the resident and invasive species affects the survival rate. Survival of the resident species from one year to another is therefore assumed to also be determined by a factor $e^{-\sum_{a}\left(\beta^{a j} R_{t}^{a j}+\mu^{a j} I_{t}^{a j}\right)}$, which is decreasing in the number of residents and invaders. ${ }^{2}$ The coefficient $\beta^{a j}>0$ is an indicator of the carrying capacity of the environment, or equivalently, the density dependence of a species with regard to its own population. The coefficient $\mu^{a j}>0$ is a measure of the competition between the two species and can be thought of as a measure of the dietary or habitat overlap. It is assumed that only individuals above age $\underline{h}$ are captured through harvesting. The number of individuals in different cohorts of the resident species at time $t=0$ is given by $\bar{R}_{0}^{a j}$.

\footnotetext{
2 The reason for assuming a symmetric impact on both survival and reproduction is that a larger impact on reproduction would mainly be disadvantageous for type $B$ species, and vice versa. In addition, the assumption that density affects both survival and reproduction is well motivated from an ecological standpoint (Myers 2001).
} 
Individuals of the resident species are assumed to reach maturity at the age of $\underline{a}$, and continue to reproduce until they die at an age of $\bar{a}$. Resident species recruitment, i.e. the number of 0 -year-olds added to the stock, is determined by:

$$
R_{t}^{0 j}=\sum_{a \geq \underline{a}}^{\bar{a}}\left[R_{t}^{a j} s^{0 j} e^{-\sum_{a}\left(\beta^{0 j} R_{t}^{a j}+\mu^{0 j} I_{t}^{a j}\right)} m^{a j} e^{-\sum_{a}\left(\beta^{a j} R_{t}^{a j}+\mu^{a j} I_{t}^{a j}\right)}\right] \forall j=A, B,
$$

where $m^{a j} e^{-\sum_{a}\left(\beta^{a j} N_{t}^{a j}+\mu^{a j} I_{t}^{a j}\right)}$ is the gross number of offspring produced, and $s^{0 j} e^{-\sum_{a}\left(\beta^{0 j} N_{t}^{a j}+\mu^{0 j} I_{t}^{a j}\right)}$ is their survival rate in the same year. This implies that offspring production is affected by inter- and intra-species competition in a similar manner as survival, through the term $e^{-\sum_{a}(\cdot)}$. Recruitment is thus here modelled as a modified Ricker (1954) recruitment function, allowing recruitment to be affected by competition between species. This choice of recruitment function implies that the resident species' recruitment declines for resident population densities close to the carrying capacity, and for high invader population densities.

Stock dynamics of the invading species are defined by:

$$
\begin{aligned}
I_{t+1}^{a+1, j} & =I_{t}^{a j} s^{a+1, j} e^{-\sum_{a}\left(\beta^{a j} I_{t}^{a j}+\mu^{a j} R_{t}^{a j}\right)}+\bar{V}_{t}^{a j}-W_{t+1}^{a+1, j} \\
\forall j & =A, B, \text { and } \forall a=0,1, \ldots, \bar{a},
\end{aligned}
$$

where

$$
\begin{aligned}
& W_{t}^{a j}=0 \quad \forall a<\underline{g}, \\
& W_{t}^{a j} \geq 0 \quad \forall \underline{g} \leq a \leq \bar{a} \text { and }
\end{aligned}
$$

where $\bar{V}_{t}^{a j}$, with $\bar{V}_{t}^{a j} \geq 0$, is the number of individuals of cohort $a$ of the invading species entering the habitat in time period $t$, and $W_{t}^{a j}$ is the number of invaders subject to control in time period $t+1$. It is assumed that no individual below age $g$ is captured.

Invader recruitment is analogous to that of the resident:

$$
I_{t}^{0 j}=\sum_{a \geq \underline{a}}^{\bar{a}}\left[I_{t}^{a j} s^{0 j} e^{-\sum_{i}\left(\beta^{0 j} I_{t}^{a j}+\mu^{0 j} R_{t}^{a j}\right)} m^{a j} e^{-\sum_{a}\left(\beta^{a j} I_{t}^{a j}+\mu^{a j} R_{t}^{a j}\right)}\right] \forall j=A, B
$$

Socially optimal management of the habitat requires maximization of the net present value from joint management of the two species. It is assumed that harvests are sold on a market, where the seller is a price-taker. Revenues from harvests, $T R_{t}$, are then:

$$
T R_{t}=p^{j} \sum_{a \geq \underline{h}} w^{a j} H_{t}^{a j}
$$


where $p^{j}$ is the price per kilo of the resident species, respectively, and $w^{a j}$ is the agespecific weight of species of type $j$. The total cost for harvesting the resident species and controlling the invader, $T C_{t}$, is:

$$
T C_{t}=\eta^{j}\left(\sum_{a \geq \underline{h}} w^{a j} R_{t}^{a j}\right)^{\gamma^{j}}\left(\sum_{a \geq \underline{h}} w^{a j} H_{t}^{a j}\right)^{\delta^{j}}+\psi^{j}\left(\sum_{a \geq \underline{h}} w^{a j} I_{t}^{a j}\right)^{\theta^{j}}\left(\sum_{a \geq \underline{h}} w^{a j} W_{t}^{a j}\right)^{\tau^{j}},
$$

where the first term is the harvesting cost and the second the control cost. In the first term, $\gamma^{j}$ is the stock elasticity, $\delta^{j}$ the output elasticity and $\eta^{j}$ a calibration parameter (Danielsson et al. 1997; Sandberg 2006) which define costs for harvesting the resident species. Following Olson and Roy (2005) costs for controlling the invader are assumed to depend on the magnitude of control as well as on the stock of the invader. In the second term $\theta^{j}$ and $\tau^{j}$ are the stock and output elasticities, respectively, and $\psi^{j}$ is a calibration parameter which together determine costs for capturing the invader.

Gear selectivity has achieved considerable attention in the fishery literature (Clark 1990; Skonhoft et al. 2012). Many fishing technologies imply that a manager often cannot choose to target a single age-class or a certain size of fish, or not even a certain species, but instead, a mixture of different age-classes, sizes and species are harvested simultaneously. Such non-selectivity in harvesting is not only relevant for fish, but can also apply for land-living species, e.g. when traps or snares are used (Damania et al. 2005). Depending on the species considered, harvesting of the resident species can thus be more or less selective with regard to the composition of ageclasses captured. ${ }^{3}$ When the management goal is the maximization of present value profit for a single species, non-selectivity typically implies that the optimal solution is characterized by pulse harvesting (Clark 1990). In the context of this paper, we are mainly interested in the implications of non-selective harvesting of the resident species for the choice of policy directed towards an invasive species. We will therefore consider two different situations: knife-edge selective harvesting, where the manager is assumed to have complete freedom to choose the composition of age-classes captured, and non-selective harvesting, where equal proportions of all age-classes are captured. Thus, under non-selectivity we have an additional constraint:

$$
\frac{H_{t}^{a j}}{R_{t}^{a j}}=\frac{H_{t}^{b \neq a, j}}{R_{t}^{b \neq a, j}} \quad \forall a, b \geq \underline{h},
$$

whereas under knife-edge selectivity the manager is free to choose the composition of age-classes in the harvest as long as $a \geq \underline{h}$.

Profits in a given time period, $\pi_{t}$, are defined by:

$$
\pi_{t}=T R_{t}-T C_{t},
$$

and the total net present value, $T N P V$, is given by:

\footnotetext{
3 We choose here not to include non-selectivity in control, as the interpretation of the control subsidy is not straightforward.
} 


$$
T N P V=\sum_{t=0}^{T} \rho^{t} \pi_{t}
$$

where $\rho^{t}=(1 /(1+r))^{t}$ is the discount factor with $r$ as the annual discount rate. The manager of the two-population system is assumed to choose harvests and control in order to maximize (9) given (1)-(8) and non-negativity constraints $R_{t}^{a j} \geq 0$ and $I_{t}^{a j} \geq 0$. Setting up the discrete time dynamic Lagrangian expression and solving for the Kuhn-Tucker first order conditions (Tahvonen 2009; Conrad 2010), gives the equations for the development of $H_{t}^{a j}, W_{t}^{a j}, R_{t}^{a j}$ and $I_{t}^{a j}$ along the optimal path (see Appendix).

\section{Optimal regulation and policy choice under open access}

Assume there is a habitat, where there is only a single resident species present, which is harvested under open access conditions. Due to the lack of well-defined property rights, there is a risk that too much of the species is harvested. In this situation, a well designed harvesting tax could lead to harvests being optimally allocated over time from a social perspective. If an invader enters the ecosystem, the level of such a harvesting tax should be adjusted upwards; this would lead to an increase in the resident population and thereby, the invader can be crowded out. If, on the other hand, the harvesting tax is left unadjusted, it would still be possible to introduce a subsidy for control of the invader, which would reduce the number of invaders. More generally, however, a better outcome could be achieved if policy makers consider both alternatives and identify the best possible combination of the two instruments. Their relative stringency should then, optimally, be determined taking into account their respective impact on the net present gains from harvesting the resident species. In the following we investigate how the level of these two policy instruments is determined in an optimal manner.

The economically optimal harvesting of the resident species and control of the invader are obtained from the first-order conditions for the above described optimization problem (see Appendix). From these first order conditions the optimal harvesting tax and control subsidy can be identified, as will be shown in the following.

From Eq. (14) in the Appendix, we find that the optimal harvest of age cohort $a$ of the resident species at time $t$ is obtained where the marginal benefits equals the sum of marginal harvesting and user cost according to:

$$
T R_{H^{a j} t}^{\prime}-T C_{H^{a j} t}^{\prime}+\sum_{b \neq a} \frac{\chi_{t}^{a, b \neq a, j}}{R_{t}^{a j}}=\lambda_{t}^{a j},
$$

where $T R_{H^{a j_{t}}}^{\prime}>0, T C_{H^{a j_{t}}}^{\prime} \geq 0, \chi_{t}^{a, b \neq a, j} \leq 0, \lambda_{t}^{a j} \geq 0$.

Proof see Appendix

The first term at the LHS of Eq. (10) constitutes the marginal benefit, i.e. the price paid per harvested individual of the resident species belonging to age-class $a$, the 
second the marginal cost of harvesting one additional individual of the same ageclass, and the third the cost of non-selectivity in harvesting. The Lagrange multiplier at the RHS of (10), $\lambda_{t}^{a j}$, is the current value of the future stock of the resident species, i.e. the well-known marginal user cost. The marginal user cost reflects the foregone future net benefits from reductions in the populations caused by the harvesting in time $t$. Under open access conditions, the optimal level of a harvesting tax equals the marginal user cost (Clark 1990; Conrad 2010). ${ }^{4}$ Under complete selectivity, the use of a harvesting tax then implies that harvesting stops when the marginal cost of harvesting has increased to a level equal to the market price minus the harvesting tax. In that case the harvesting tax ensures that the population is optimally managed over time, provided that the marginal cost of harvesting increases when the stock declines. A harvesting tax can therefore be motivated even if there is no invasion. ${ }^{5}$

If, however, an invasive species enters the ecosystem this can motivate an adjustment of the level of the harvesting tax. It is therefore of interest to investigate the components of the tax. To do this, we solve Eq. (16) in the Appendix for the harvesting tax $\lambda_{t}^{a j}$. The resulting Eq. (11) shows that $\lambda_{t}^{a j}$ increases when considering the existence of a competing invader:

$$
\begin{aligned}
\lambda_{t}^{a j}= & -T C_{R_{t}^{a j}}+\rho \sum_{a=0}^{\bar{a}} \lambda_{t+1}^{a+1, j} R_{R_{t}^{a j}, t+1}^{a+1, j}+\lambda_{t}^{0 j} R_{R_{t}^{a j}, t}^{0 j} \\
& +\rho \sum_{i=0}^{\bar{i}} \varpi_{t+1}^{a+1, j} I_{R_{t}^{a j}, t+1}^{a+1, j}+\varpi_{t}^{0 j} I_{R_{t}^{a j}, t}^{0 j} \\
& -\sum_{b} \chi_{t}^{a, b \neq a, j} \frac{H_{t}^{a j}}{\left(R_{t}^{a j}\right)^{2}}
\end{aligned}
$$

where $T C_{R_{t}^{a j}}^{j} \leq 0, R_{R_{t}^{a j}, t+1}^{a+1, j}, R_{R_{t}^{a j}, t}^{0 j} \geq 0, I_{R_{t}^{a j}, t+1}^{a+1, j}, I_{R_{t}^{a j}, t}^{0 j} \leq 0,, \lambda_{t}^{a j} \geq 0, \varpi_{t}^{a j}, \chi_{t}^{a j} \leq$ 0

\section{Proof see Appendix}

Equation (11) shows that the optimal harvesting tax per individual of age cohort $a$ harvested at time $t$ is increasing in the stock effect on cost (first term at the right hand side), in impact on marginal value of the recruitment and survival of the resident species (second and third term) and the invader (fourth and fifth terms), and increasing in the net marginal cost of non-selectivity in harvesting (last term).

\footnotetext{
4 Other management regimes than open access regimes can be relevant for commercial species. Further analysis of policy instruments in the presence of invaders under different regimes is an important topic, but is likely to require a quite different model.

5 Harvesting taxes or, equivalently, landing fees, have mainly been analyzed as a means to regulate fisheries. Although harvesting taxes are nowhere applied with a purpose meet a certain target for total catch, the lack of use might rather be the consequence of tradition and industry opposition against the additional costs they would incur because of the tax (Hannesson and Kennedy 2005).
} 
Noting the one-to-one relationship between $R_{t}^{a j}$ and $H_{t-1}^{a-1, j}$, see Eq. (1), the terms $\rho \sum_{i=0}^{\bar{i}} \varpi_{t+1}^{a+1, j} I_{R_{t}^{a j}, t+1}^{a+1, j}$ and $\varpi_{t}^{0 j} I_{R_{t}^{a j}, t}^{0 j}$ in Eq. (11) indicate the marginal increase in next periods harvesting cost if we harvest more of the resident species now, because increased invader growth reduces the future stock of the resident species. With respect to life-history of the resident species, the tax is relatively high for cohorts of the resident species with high reproduction and survival, such as is the case for older cohorts of type $B$, where $R_{R_{t}^{a j}, t}^{0 j}$ and $R_{R_{t}^{a j, t+1}}^{a+1, j}$ are both large. The reason is the foregone future profit from harvesting the same individual or its offspring at a later date, where this foregone profit is larger at high growth and survival rates. In a corresponding manner, the tax is low for cohorts of a resident species with low reproduction and survival (i.e. with relatively low $R_{R_{t}^{a j}, t}^{0 j}$ and $R_{R_{t}^{a j}, t+1}^{a+1, j}$ ), such as is relevant for older age cohorts of a type $A$ species.

Finally, looking at Eqs. (10) and (11) we find that there are two effects of nonselectivity in harvesting. First, from Eq. (10), non-selectivity implies that a smaller harvesting tax on cohort $a$ is motivated because non-selectivity implies that harvesting is less profitable than would otherwise be the case. Second, from Eq. (11), a higher tax on a cohort is motivated if an increase of that particular cohort effectively relaxes the constraint that non-selectivity imposes of harvesting profits.

Control subsidies, or bounties, have been used in different settings in order to manage unwanted species in the environment (Heide-Jørgensen and Härkönen 1988; Allen and Sparkes 2001). We derive the optimal control subsidy from Eqs. (15) and (17) in the Appendix. The optimal subsidy per unit of invader which belongs to cohort $a$ at time $t$, which equals $\left(-\varpi_{t}^{a j}\right)$, is then determined where the marginal control cost equals the marginal net benefit of a decrease in the population of a cohort according to:

$$
\begin{aligned}
T C_{W_{t}^{i j}}= & \left(-\varpi_{t}^{a j}\right)=T C_{I_{t}^{a j}}^{j}-\rho \sum_{a=0}^{\bar{a}} \lambda_{t+1}^{a+1, j} R_{I_{t}^{a j}, t+1}^{a+1, j}-\lambda_{t}^{0 j} R_{I_{t}^{a j}, t}^{0 j} \\
& -\rho \sum_{a=0}^{\bar{a}} \varpi_{t+1}^{a+1 j} I_{I_{t}^{a j}, t+1}^{a+1, j}-\varpi_{t}^{0 j} I_{I_{t}^{a j}, t}^{0 j},
\end{aligned}
$$

where $T C_{W_{t}^{i j}} \geq 0, T C_{I_{t}^{a j}}^{j} \leq 0, R_{I_{t}^{a j}, t+1}^{a+1, j}, R_{I_{t}^{a j}, t}^{0 j} \leq 0, I_{I_{t}^{a j}, t+1}^{a+1, j}, I_{I_{t}^{a j}, t}^{0 j} \geq 0, \lambda_{t+1}^{a+1, j} \geq$ $0, \varpi_{t}^{a j} \leq 0$.

\section{Proof see Appendix}

Noting that $\varpi_{t}^{a j}<0$, and observing the similarity with Eq. (11), Eq. (12) shows that the value of the optimal control subsidy, $\left(-\varpi_{t}^{a j}\right)$, is decreasing in the marginal stock impact on control cost (first term), increasing in the marginal value of the impact on resident species' survival and reproduction (second and third terms), and increasing in the marginal value of the impact on survival and reproduction of the invader (two last terms). The subsidy is thus large when the marginal stock effect on control costs 
is low implying that there are little gains from postponing control until the stock is larger and control costs hence cheaper. The subsidy is high (i) when there is strong competition with the resident species such that control has a significant impact on the harvested value and (ii) if the invader population growth is not already constrained by the carrying capacity, where the latter implies that the terms $I_{I_{t}^{a j}, t+1}^{a+1, j}$ and $I_{I_{t}^{a j}, t}^{0 j}$ are small. Carrying capacity is less likely to constrain the invader if, e.g. the invader population is small, if the species is highly flexible in its choice of food or requires little habitat space.

When comparing the optimal choice of control of the invader with harvesting of the resident species we can conclude that in each period of time, and for a given cohort, control is preferred to harvesting of the resident species if (i) marginal control costs are low and marginal benefits from harvesting are large, (ii) the invading age cohort is highly reproductive, e.g. if the invader is a mature individual of type $B$, or many individuals in the invader population have reached a highly reproductive age, (iii) the resident species' reproduction is low, valid for a type $A$ resident, implying that a reduction of harvests has little impact on the resident population numbers in the short term so that the invader cannot be crowded-out in an effective manner, (iv) control costs are insensitive to increases in invader population, implying that there is no reason to postpone control because it will be less costly in the future, and (v) the marginal cost of harvesting is rapidly increasing in harvest, implying that variations in harvesting costs are more expensive to the manager. The latter implies that harvest adaptation, i.e. a reduction in harvests of the resident species in order to crowd out the invader, at a critical time stage of an invasion is more costly. Since invasions can take place for different combinations of age-classes and species types, the optimal allocation of control and harvest and associated subsidies and taxes, respectively, can be determined only by numerical analysis. Also, the impact of non-selectivity in harvesting of the resident species on the optimal control subsidy is difficult to derive analytically, and must therefore also be investigated numerically.

\section{Data}

An empirical application of the theoretical model requires data on revenue and cost functions, and parameter values for reproduction, survival, and interaction between the resident and invasive species for different cohorts. Although there is relatively much data on revenues and costs for commercially valuable species, and on reproduction and survival of those, data on competition among a resident and invasive species as well as estimations of control costs for invaders are lacking. Therefore, generic data from Järemo and Bengtsson (2011) are used, which illustrate the typical life history of type $A$ and $B$ species. Both species are assumed to have a life span of six years, which implies that we have six age cohorts, with $a=0, \ldots, 5$. Survival data illustrate the characteristics of the different species types, described above. Hence, a type $B$ species has a higher reproduction than type $A$, but a lower juvenile survival. Reproduction parameters are calibrated such that both species have the same finite rate of increase at a stable age distribution and density independence. In the absence of competition 
Table 1 Population data used in model

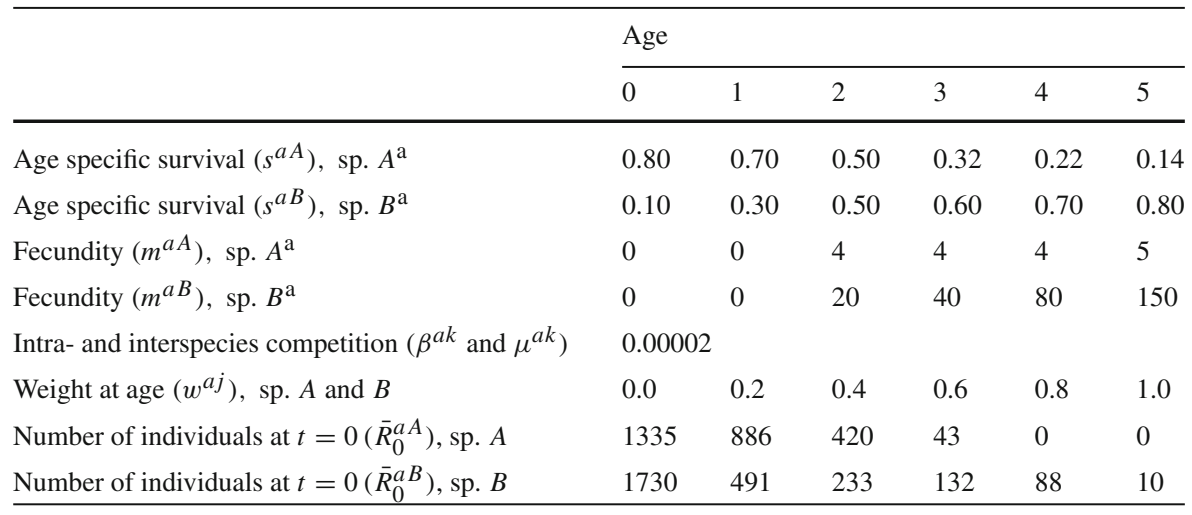

a Järemo and Bengtsson (2011)

between species, the age of highest reproductive value ${ }^{6}$ is three for a type $A$ organism and five for a type $B$. The age specific intra- and inter-species competition effects, $\beta^{a j}$ and $\mu^{a j}$, are subjectively set to 0.00002 for all age classes and species. The assumption about equal intra- and interspecies competition implies that the resident and invasive species are fully similar with regard to their use of the limited resource (food or space). This assumption facilitates the isolation of the impact of life-history on the optimal policy instrument choice. The age-specific weight is assumed to increase linearly with age and is normalized to 1 for 5-year olds of both species. All parameter values that characterize the life histories of the different species types are given in Table 1.

We assign identical economic parameters to both species types except for the output elasticity. The price of harvest, $p^{j}$ in Eq. (5) is normalized to one. Harvest and control technologies are assumed to have similar parameters. It is presumed that only individuals of age 2 or older can be harvested or controlled, respectively. The size of the stock elasticity in Eqs. (6) and (7) depends on whether we have group-living or solitary species. For group-living species a stock elasticity less than minus one can generally be expected (Bjørndal 1987, 1988). We assign the value -1 to $\gamma^{j}$ and $\theta^{j}$, thereby assuming that the species are relatively uniformly dispersed over the habitat. Output elasticity is determined by the size of scale economies in harvesting and control. Here, the output elasticity of harvest and control costs, $\delta^{j}$ and $\tau^{j}$, are assumed to equal to 1 for harvest and to 3 for control, implying a linear harvesting cost function, and rapidly increasing costs of control. The higher output elasticity of the control cost function is motivated because control costs are likely to exceed harvesting costs in many real world settings, e.g. because the behavior of invaders' is usually less known than the behavior of resident species, and control technologies are often not well established, compared to technologies for harvesting of commercially valuable species. In particular, control costs can be high in a marine environment compared to a terrestrial one due to the smaller range and lower efficiency of control technolo-

\footnotetext{
6 The age with the highest expected reproduction of an individual from their current age onward, given that they have survived to their current age.
} 
gies available (Bax et al. 2003; Secord 2003; Ling 2009). ${ }^{7}$ The calibration parameters $\eta^{j}$ and $\psi^{j}$ are set to 1 . The initial vector $\bar{R}_{0}^{a j}$ is set as the steady-state stock in the economic profit-maximizing equilibrium with harvest in the absence of invaders and the discount rate $r$ is set to 3 percent, as suggested by e.g. Boardman et al. (2011) to be in concordance with values used for cost-benefit analysis of public projects. In the following, optimal harvests are simulated over 50 years. All calculations are made using GAMS (Brooke et al. 1998) software and CONOPT2 solver. Given possible non-convexity of the model, the model has also been run with a globally maximizing solver, BARON, which gives similar results.

\section{Results}

Given that both resident and invasive species can have one out of two different life history types, there are four different possible combinations of these species types. Furthermore, invasions can be made by individuals belonging to six different age classes. In the following, we make calculations for invasions of ten individuals of a given age and type in each time period. We investigate in total 24 different scenarios, each with a different combination of species types and different age class of the invader. Calculations are made of the optimal combination of harvest and control, and associated tax and subsidy respectively. Differences in results that arise when the resident species is harvested under non-selectivity are discussed.

\subsection{Trade-off between harvest and control}

Once a larger population of the invader is established, the trade-off between harvest adaptation and control is, essentially, determined by (i) the variation in damage caused by invaders belonging to different age classes, where larger variation between age classes implies that control is favored over adaptation because the most damaging age classes can be targeted, and (ii) the costs of control versus harvest adaptation. Adaptation is, generally, more efficient with a resident type $B$ species for both invader types, see Fig. 1.

The high reproduction of the marginally harvested age class of a resident type $B$ implies that reduced harvesting leads to a rapid crowding-out of the invader. The largest resident population increase occurs with a resident type $B$ and an invader type $A$ age 2. Effectiveness of harvest adaptation combination with a high expected reproduction over the remaining life span for type $A$ of age 2 is likely to explain this. Notably, both control and harvest adaptation is low for a resident of type $B$ with an invasion of juveniles of type $B$, as both measures are little necessary when mortality of the invading age-class is high. Control is on the overall larger when there is a resident of type $A$, given the invader type and age, and this is explained by harvest adaptation

\footnotetext{
7 Results are insensitive to assumptions about the cost level, $\psi^{j}$, as well as to stock elasticity in the control cost function. If, however, the output elasticity of the control cost function is high, implying rapidly increasing marginal cost of control, harvest adaptation can be included to a significant extent in optimum. We therefore include scenarios with different output elasticity.
} 


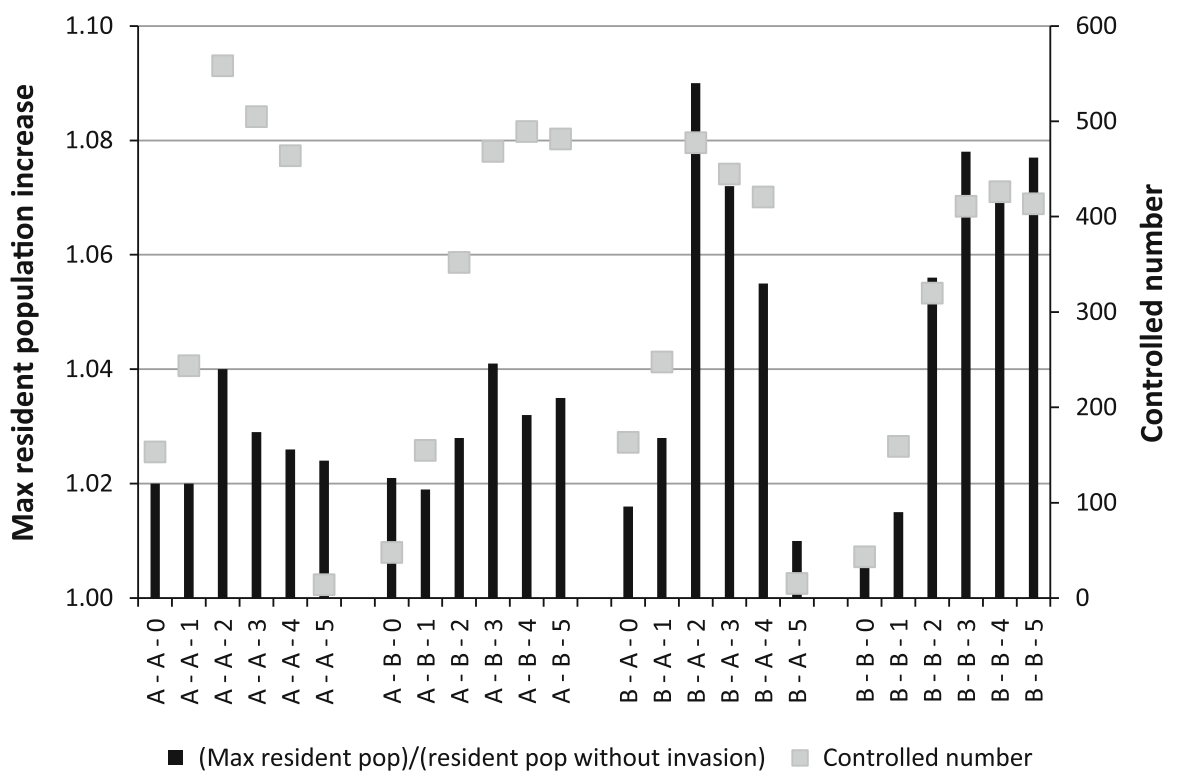

Fig. 1 Harvest adaptation and invader control when $\theta^{j}=3$. Note Harvest adaptation is measured as the maximum increase in the resident species population compared to the initial level, i.e.max $\left\{\left(\sum_{a} R_{t}^{a j} / \sum_{a} \bar{R}_{0}^{a j}\right)\right\}$, shown on the left vertical axis. Control is measured as the total number controlled over 50 years, i.e. $\sum_{t} \sum_{a} W_{t}^{a, j}$, shown on the right vertical axis. Invasion scenarios are indicated on the horizontal axis by "resident species type-invader species typ-invader age"

being little effective. The largest total number of invaders controlled is found when there is a resident of type $A$ and two-year old invaders of the same type.

With respect to the development of control and harvest during time, control is supplemented with a harvest reduction in order to crowd-out the invader in the medium term, which is illustrated for the case when the resident species is a B type and the invader an $A$ type, see Fig. 2. However, if the output elasticity is reduced from $\theta^{j}=3$ to $\theta^{j}=1$, harvest adaptation is not included in the solution because it is a more blunt measure than control as the most damaging individuals cannot be targeted (see Appendix B). This implies that the resident population is maintained at almost the same level as when there is no invasion.

\subsection{Optimal harvest taxes and control subsidies}

If the resident species is subject to open access harvesting, a harvesting tax is motivated also in the absence of a biological invasion, but the biological invasion motivates a higher harvesting tax than would otherwise be the case, as shown in Sect. 2. The increased harvesting tax leads to a larger resident population which crowds out the invader. This will also negatively affect survival and reproduction of the resident species, but that negative effect is partly offset by reduced harvesting costs when the resident population increases. In Fig. 3, the optimal harvesting tax with and without an 


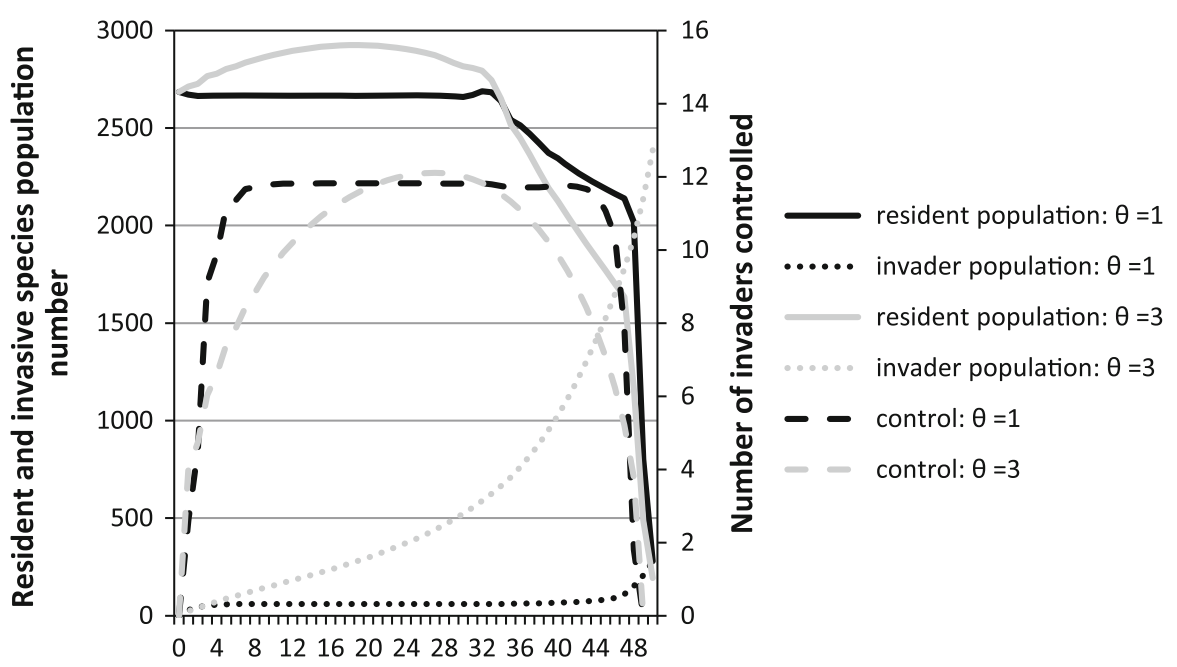

Fig. 2 Resident and invader population and control of invaders in a scenario with a type $B$ resident and invader type $A$ age 2. Comparison of the cases where $\theta^{j}=1$ and $\theta^{j}=3$. Note: Resident population is measured as $\sum_{a} R_{t}^{a j}$, invader population is measured as $\sum_{a} I_{t}^{a j}$, and control is measured as $\sum_{a} W_{t}^{a j}$

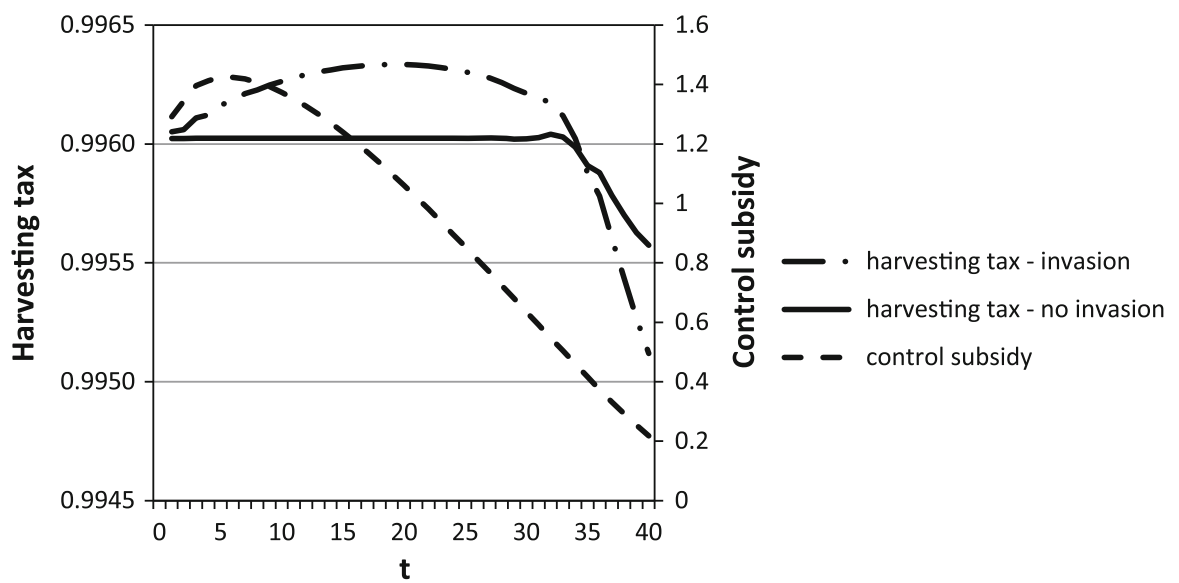

Fig. 3 Harvesting $\operatorname{tax}\left(\lambda_{t}^{5 B}\right)$ in current terms for a resident $B$ type age 5, with and without an invasion of 2-years olds of type $A$, and control subsidy $\left(-\varpi_{t}^{2 A}\right)$ for type $A$, age 2 , when $\theta^{j}=3$

invasion is shown for the case with a resident $B$, harvested under knife-edge selectivity, and an invader of type $A$ age 2 . In this scenario, only age class 5 is harvested in the optimal solution.

The results presented in Fig. 3 show that the increase in the optimal harvesting tax under an invasion is small compared to a situation without an invasion. Whereas the harvesting tax is constant without an invasion, it reaches a maximum after approximately 20 years under an invasion. The successive increase is explained by the increasing invader population, which implies that an increase in the resident population becomes 


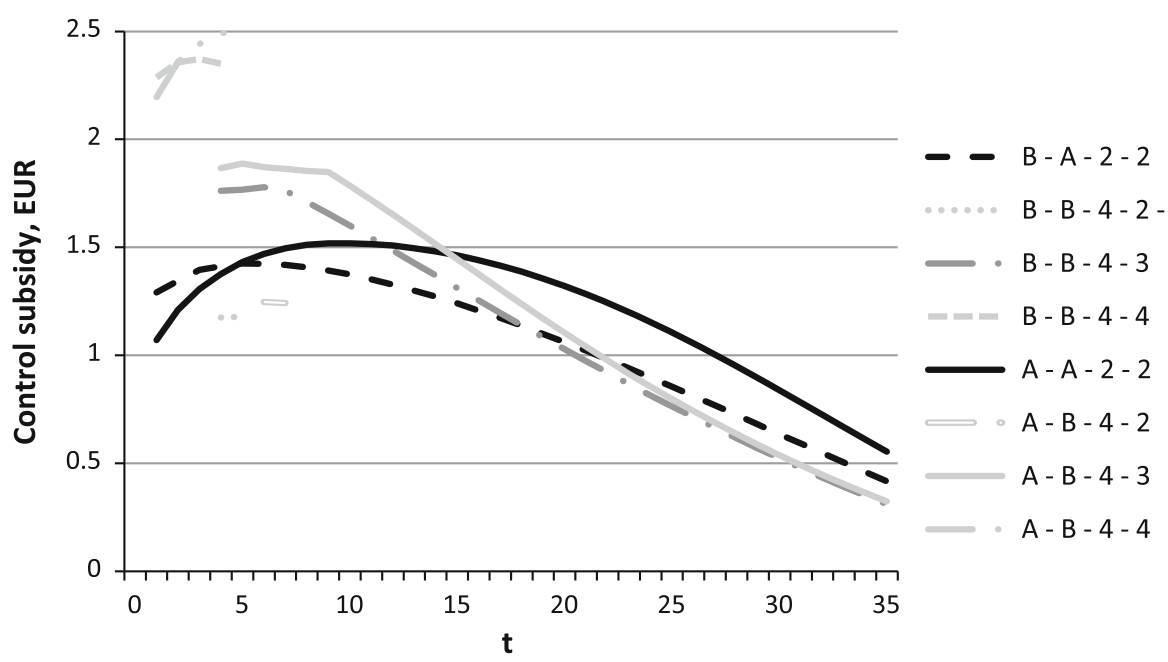

Fig. 4 Control subsidy $\left(-\varpi_{t}^{a j}\right)$ in current terms in different invasion scenarios under knife edge selectivity, $\theta^{j}=3$ Note: Data series are indicated by "resident species type—invader species type—invader age—age of controlled invader". Short lines indicate that control is only subsidized during a few time periods

more effective. The associated control subsidy is included in the same figure. In the chosen scenario, only age class 2 is subject to control. The control subsidy reaches a maximum after 5 years, and then decreases successively over time as the invader population increases. The high level in early time periods is due to high net present cost of controlling a small population in the first years in combination with a high benefit of control, whereas the subsequent decrease is explained by successively lower costs for control as the invader population increases.

The pattern of the control subsidy differs for different combinations of resident and invading species, and their life history. However, a common feature is the increase in the subsidy during early years, followed by a rapid or monotonic decline. This is shown in Fig. 4 for four scenarios with an $A$ or $B$ resident type, harvested under knife-edge selectivity, and invasions of either 2-year-olds of type $A$, or 4-year-olds of type $B$. These invasion scenarios are chosen because they are associated with comparatively high economic damages as the invader population grows faster than with other invading age classes.

The comparison shows that with a type $A$ invader (indicated by black curves), control subsidies are increased over the first time periods and reach a maximum after 5-10 years, the earlier maximum with a $B$ resident. With a type $B$ invader (indicated by grey curves), more age classes are controlled in earlier periods, with a higher subsidy for older age classes. After a couple of time periods, only control of age class 3 is subsidized, and subsidies are successively reduced for the same reason as above. Larger subsidies are optimal with a type $A$ resident given the type of invader, due to a combination of harvesting adaptation being more costly with an $A$ resident and a higher harvested biomass and hence higher harvesting profits at stake. 


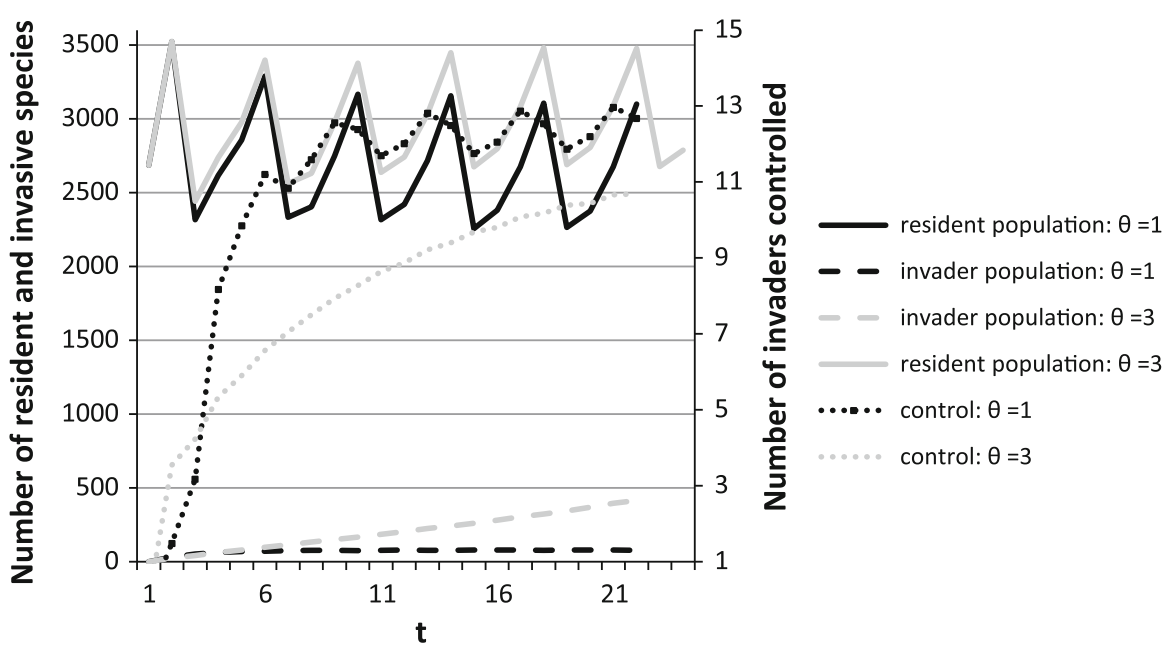

Fig. 5 Resident and invader population and control of invaders in a scenario with a type $B$ resident and invader type $A$ age 2 under non-selectivity. Resident population equals $\sum_{a} R_{t}^{a j}$, invader population equals $\sum_{a} I_{t}^{a j}$, and control equals $\sum_{a} W_{t}^{a j}$

\subsection{Implications of non-selectivity}

The introduction of the more realistic case of non-selectivity in harvesting of the resident species has two main effects; pulse harvesting of the resident species and fluctuating or smoothly decreasing control subsidies depending on control cost, see Fig. 5.

When the control cost is relatively low $\left(\theta^{j}=1\right)$, control increases successively over the first years as the invader population increases and it becomes less costly to locate individuals. Thereafter, the highest control is carried out the year before a pulse harvest, and the smallest control the year after the harvest, i.e. when the resident population is the smallest. Increased control before harvesting implies that the resident population is larger at the time of harvesting than it would otherwise be. This reduces harvesting cost. Varying the amount of control is more effective if the harvestable fraction of resident population number will quickly respond to improved conditions for reproduction and survival. Here, it is thus the short term impact of control on the invader that is of interest, wherefore the impact on the resident species survival is more important, while the impact on its reproduction is less important as most of the juveniles will not reach harvestable age before the pulse harvest. Control of age class 2 is particularly effective in keeping the invading $A$ type population low, as this age class constitutes a large share of the mature population. This implies that the invader population is reduced both because of the numbers directly controlled, and because of reduced reproduction. The invader population develops in a similar manner as in the same invasion scenario with knife-edge selectivity - it is kept at a low and stable level.

If, instead, the marginal cost of control increases $\left(\theta^{j}=3\right)$, the optimal path of control is changed. Control then increases smoothly over time as the invader population increases. With increasing marginal cost of control, variations in control become more 


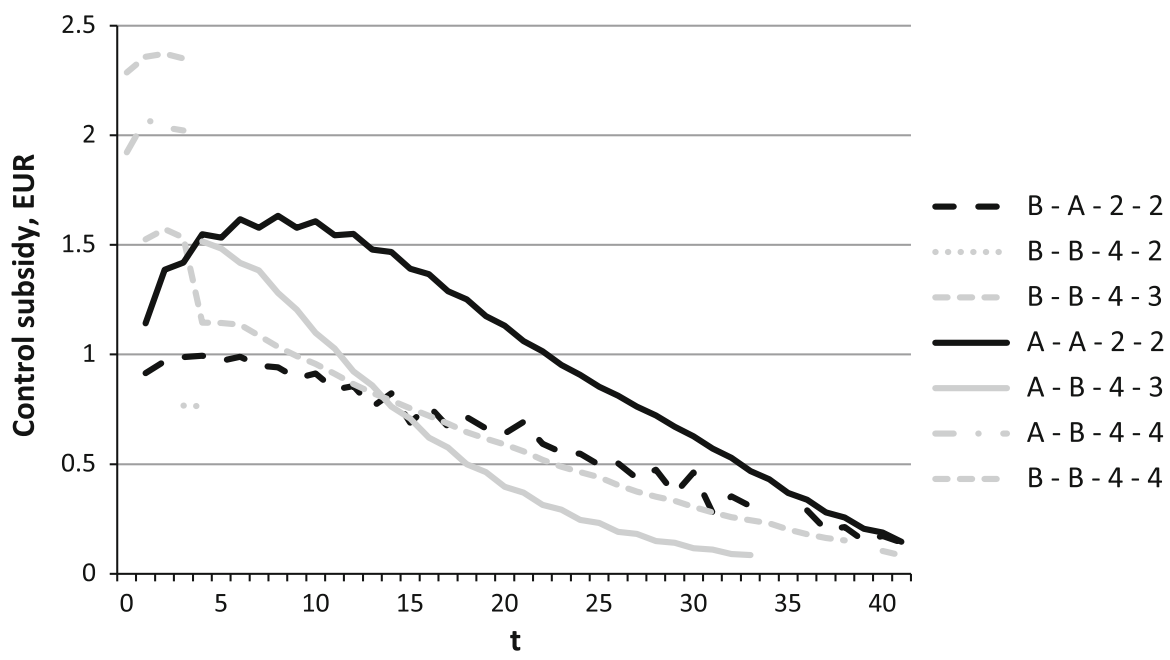

Fig. 6 Control subsidy $\left(-\varpi_{t}^{a j}\right)$ in current terms in different invasion scenarios under non-selectivity, $\theta^{j}=3$ Note: Data series are indicated by "resident species type-invader species type-invader age—age of controlled invader". Short lines indicate that control is only subsidized during a few time periods

costly, which explains this. With higher marginal cost of control, there is less control, and control is partly replaced by harvest adaptation, reflected in a higher resident population level.

Comparing control subsidies in Fig. 3 with those under non-selectivity in Fig. 6, shows that in the latter case, control subsidies are lower in all scenarios, except the one with a type $A$ resident and invader. The main explanation of the former is the lower net present profit from harvesting due to non-selectivity. In the scenario with type $A$ as both resident and invader, net present profits are reduced under non-selectivity. In spite of this, the control subsidy is maintained at approximately the same level as under knifeedge selectivity, since variable control is more effective in terms of its impact on both resident and invader population if both belong to type $A$, given the larger importance of survival of a resident $A$ type for the future population, and the advantage of controlling an invading type $A$ species given that this successfully reduces its regeneration. Also different from the case with knife-edge selectivity is the fluctuation in the control subsidy, in particular in the case with a type $A$ invader. First, variations in control are costly because of the rapidly increasing marginal cost. Therefore, control is only varied if the positive effect on the resident population outweighs the extra cost. As discussed above, control efficiently reduces both the numbers but also reproduction with a type $A$ invader as control is directed towards a large share of the mature population. Control of a type $A$ invader age class 2 is therefore particularly effective in the short term.

\section{Discussion and conclusions}

Using a model of optimal co-management of one resident and one invading species, we examine the optimal combination of harvest of a resident species and control of an invader, and the associated implications for the use of policy instruments. The policy 
instruments considered are a harvesting tax for the resident species and a control subsidy for the invader. These issues are analyzed with a focus on species life history and invader age for the trade-offs made. We construct a discrete dynamic optimization model, and show how it can be applied for numerical analysis of optimal regulation and policy choices.

An important conclusion from the theoretical analyses was that, under conditions of open access of the resident species, a higher harvesting tax can be motivated in the presence of an invasion, in particular when harvested cohorts are highly reproductive. More precisely, it was shown that the optimal combination of harvest tax and control subsidy for regulating the invader population is determined by the (i) marginal cost of controlling the invader (ii) losses in profits from harvesting the resident species under an invasion, and (iii) marginal impacts of the two measures on current and future streams of net benefits from the resident species. The magnitude of these factors depends on the combination of resident and invader species type, specialized in reproduction or survival, and on age classes when the invasion occurs.

The empirical illustration with a generic model which isolated the effects of combinations of life history on the optimal harvesting tax and control subsidy showed that both these policy options are always used in combination if control costs are high compared to harvesting costs. Common to both policies is the targeting on relatively highly reproductive age classes. A larger weight is placed on control when the resident species is specialized in survival because harvesting is little effective with this type of resident species. A subsidy for controlling the invader also has advantage over a harvesting tax when control costs are insensitive to variations in the invader population, implying that critical stages of invader population growth can be targeted without a considerable increase in costs, and when harvesting costs are sensitive to harvest variations.

With respect to the development of the stringency of the policies over time, it was demonstrated that the harvesting tax in current terms increases over time as the invader population grows until the invader population growth levels off because of density dependence. The optimal subsidy for control of the invader first increases as damages from the invader increases, then falls over time as invader population increases and control costs therefore fall provided that the marginal cost is sensitive to variations in invader population. Our empirical calculations also showed that if the resident species is harvested with a non-selective method, which typically implies that pulse harvesting is optimal, it can be optimal to let control subsidies for the invader vary between higher and lower levels in order to create an additional increase in the resident population just before the harvest. Variations in the control subsidy are more effective if the invader is specialized in survival, because invaders specialized in reproduction will to larger extent respond to control by increased reproduction when reproduction is density-dependent.

Our results indicate differences in the choice of control and adaptation strategies for invasive terrestrial and aquatic species. Certain terrestrial species, such as mammals, are through evolution specialized in survival (Deevey 1947; Polis and Farley 1980). When this type of resident species is commercially harvested, harvest adaptation is thus an inefficient tool and higher subsidies for control of invaders can be motivated. The literature suggests that control technologies are to large extent available and less 
costly for the protection of terrestrial species compared to marine species (Bax et al. 2003; Secord 2003; Ling 2009). Taken together, this suggests that control subsidies are particularly relevant as a policy instrument in a terrestrial environment. In a marine environment, this is less likely to be the case. If we have, instead, a harvested marine species which is specialized in reproduction, such as fish, harvest taxation can be worth considering as a policy tool to limit the economics damages from invading species when the species compete for scarce resources both because control may not be possible, and because harvest adaptation can be efficient in limiting the growth of the invader. If a resident species is harvested with a non-selective technology, the optimal control subsidies are lower than otherwise. Non-selectivity is often relevant for fishery, and results then suggest that changes in the harvesting technology need to be taken into consideration when designing policy instruments directed towards invaders.

There are several limitations in our study. For instance, we do not explore the role of habitat characteristics, which is likely to affect both resident and invading species, and may increase or decrease the impact of competition on the value of harvesting the resident species. In the numerical simulations, we model competition between species as symmetric. This need not be the case, but situations where one species has a larger negative impact on the other can occur. Also, it is assumed in the numerical simulations that all age cohorts are identical with regard to the role they play for inter- and intraspecies competition, which need not be the case in reality. The policy instruments investigated apply under open access conditions for harvesting of the resident species, but other situations can occur such as situations where there is market power in resource use, or where wild harvested species are managed collectively in local or regional setting. Further investigation of invasive species management which takes such conditions into account is likely to bee valuable.

Open Access This article is distributed under the terms of the Creative Commons Attribution License which permits any use, distribution, and reproduction in any medium, provided the original author(s) and the source are credited.

\section{Appendix A: Derivation of first-order conditions for optimal regulation}

The discrete time dynamic Lagrangian expression is formulated from Eqs. (1)-(10) as:

$$
L=\sum_{t=0}^{T} \rho^{t}\left\{\begin{array}{l}
T R_{t}\left(H_{t}^{a j}\right)-T C_{t}\left(R_{t}^{a j}, H_{t}^{a j} I_{t}^{a j}, W_{t}^{a j}\right)+\rho \sum_{a=0}^{\bar{a}} \lambda_{t+1}^{a+1, j}\left(R_{t+1}^{a+1, j}\left(R_{t}^{a j}, H_{t+1}^{a j}, I_{t}^{a j}\right)-R_{t+1}^{a+1, j}\right) \\
+\lambda_{t}^{0 j}\left(R_{t}^{0 j}\left(R_{t}^{a j}, I_{t}^{a j}\right)-R_{t}^{0 j}\right)+\rho \sum_{a=0}^{\bar{a}} \varpi_{t+1}^{a+1, j}\left(I_{t+1}^{a+1, j}\left(I_{t}^{a j}, W_{t+1}^{a j}, R_{t}^{a j}\right)-I_{t+1}^{a+1, j}\right) \\
+\varpi_{t}^{0 j}\left(I_{t}^{0 j}\left(I_{t}^{a j}, R_{t}^{a j}\right)-I_{t}^{0 j}\right)+\sum_{b=\underline{h}}^{\bar{b}} \chi_{t}^{a, b \neq a, j}\left(\frac{H_{t}^{a j}}{R_{t}^{a j}}-\frac{H_{t}^{b \neq a, j}}{R_{t}^{b \neq a, j}}\right)
\end{array}\right\}
$$

where $\lambda_{t}^{0 j} \geq 0, \lambda_{t}^{a j} \geq 0, \lambda_{t+1}^{a+1, j} \geq 0$ are the Lagrange multipliers for the dynamics of the resident species, $\varpi_{t}^{0 j} \leq 0, \varpi_{t}^{a j} \leq 0, \varpi_{t+1}^{a+1, j} \leq 0$ the Lagrange multipliers for the 
invader, and $\chi_{t}^{a j} \leq 0$ the multiplier for the restriction on non-selectivity in harvesting of the resident species.

Solving for the Kuhn-Tucker first order conditions, gives the following equations for the development of $H_{t}^{a j}, W_{t}^{a j}, R_{t}^{a j}$ and $I_{t}^{a j}$ along the optimal path, where subscripts denote partial derivatives.

$$
\begin{aligned}
& \rho^{-t} L_{H^{a j}}=T R_{H^{a j} t}-T C_{H^{a j} t}-\lambda_{t}^{a j}-\sum_{b \neq a} \frac{\chi_{t}^{a, b \neq a, j}}{R_{t}^{a j}} \leq 0, \\
& \rho^{-t} L_{H^{a j}} H_{t}^{a j}=0,0 \leq H_{t}^{a j}, \quad t=0,1, \ldots, T \\
& \rho^{-t} L_{W_{t}^{a j}}=-T C_{W_{t}^{a j}}-\varpi_{t}^{a j} \leq 0, \\
& \rho^{-t} L_{W_{t}^{a j}} W_{t}^{a j}=0,0 \leq W_{t}^{a j}, \quad t=0,1, \ldots, T \\
& \rho^{-t} L_{R_{t}^{a j}}=-T C_{R_{t}^{a j}}^{j}+\rho \sum_{a=0}^{\bar{a}} \lambda_{t+1}^{a+1, j} R_{R_{t}^{a j}, t+1}^{a+1, j}-\lambda_{t}^{a j}+\lambda_{t}^{0 j} R_{R_{t}^{a j}, t}^{0 j} \\
& -\rho \sum_{i=0}^{\bar{i}} \omega_{t+1}^{a+1, j} I_{R_{t}^{a j}, t+1}^{a+1, j}-\omega_{t}^{0 j} I_{R_{t}^{a j}, t}^{0 j} \\
& +\sum_{b} \chi_{t}^{a, b \neq a, j} \frac{H_{t}^{a j}}{\left(R_{t}^{a j}\right)^{2}} \leq 0 \\
& \rho^{-t} L_{R_{t}^{a j}} R_{t}^{a j}=0, \quad R_{t}^{a j} \geq 0, \quad t=0,1, \ldots, T \\
& \rho^{-t} L_{R_{t}^{0 j}}=\rho \sum_{a=0}^{\bar{a}} \lambda_{t+1}^{a+1, j} R_{R_{t}^{0 j}, t+1}^{a+1, j}+\lambda_{t}^{0 j}\left(R_{R_{t}^{0 j}, t}^{0 j}+1\right) \\
& +\rho \sum_{a=0}^{\bar{a}} \varpi_{t+1}^{a+1, j} I_{R_{t}^{0 j}, t+1}^{a+1, j}+\varpi_{t}^{0 j} I_{R_{t, t}^{0 j}}^{a j} \leq 0, \\
& \rho^{-t} L_{R_{t}^{0 j}} R_{t}^{0 j}=0, \quad R_{t}^{0 j} \geq 0, \quad t=0,1, \ldots, T \\
& \rho^{-t} L_{I_{t}^{a j}}=-T C_{I_{t}^{a j}}^{j}+\rho \sum_{a=0}^{\bar{a}} \lambda_{t+1}^{a+1, j} R_{I_{t}^{a j}, t+1}^{a+1, j}+\lambda_{t}^{0 j} R_{I_{t}^{a j}, t}^{0 j}+\rho \sum_{a=0}^{\bar{a}} \varpi_{t+1}^{a+1 j} I_{I_{t}^{a j}, t+1}^{a+1, j} \\
& -\varpi_{t}^{a j}+\varpi_{t}^{0 j} I_{I_{t}^{a j}, t}^{0 j} \leq 0 \\
& \rho^{-t} L_{I_{t}^{a j}} I_{t}^{a j}=0, \quad I_{t}^{a j} \geq 0, \quad t=0,1, \ldots, T \\
& \rho^{-t} L_{I_{t}^{0 j}}=\rho \sum_{a=0}^{\bar{a}} \lambda_{t+1}^{a+1, j} R_{I_{t}^{0 j}, t+1}^{a+1, j}+\lambda_{t}^{0 j} R_{I_{t}^{0 j}, t}^{0 j}+\rho \sum_{a=0}^{\bar{a}} \varpi_{t+1}^{a+1, j} I_{I_{t}^{0 j}, t+1}^{a+1, j} \\
& +\varpi_{t}^{0 j}\left(I_{I_{t}^{0 j}, t}^{0 j}-1\right) \leq 0,
\end{aligned}
$$




$$
\begin{aligned}
& \rho^{-t} L_{I_{t}^{0 j}} I_{t}^{0 j}=0, \quad I_{t}^{0 j} \geq 0, \quad t=0,1, \ldots, T \\
& \rho^{-(t+1)} L_{\lambda_{t+1}^{a+1, j}}=R_{t+1}^{a+1, j}\left(R_{t}^{a j}, H_{t+1}^{a j}, I_{t}^{a j}\right)-R_{t+1}^{a+1, j}=0, \quad t=0,1, \ldots, T(20) \\
& \rho^{-t} L_{\lambda_{t}^{0 j}}=R_{t}^{0 j}\left(R_{t}^{a j}, I_{t}^{a j}\right)-R_{t}^{0 j}=0, \quad t=0,1, \ldots, T \\
& \rho^{-(t+1)} L_{\varpi_{t+1}^{a+1, j}}=I_{t+1}^{a+1, j}\left(I_{t}^{a j}, W_{t+1}^{a j}, R_{t}^{a j}\right)-I_{t+1}^{a+1, j}=0, \quad t=0,1, \ldots, T \\
& \rho^{-t} L_{\varpi_{t}^{0 j}}=I_{t}^{0 j}\left(I_{t}^{a j}, R_{t}^{a j}\right)-I_{t}^{0 j}=0, \quad t=0,1, \ldots, T \\
& \rho^{-t} L_{\chi_{t}^{a, b \neq a, j}}=\frac{H_{t}^{a j}}{R_{t}^{a j}}-\frac{H_{t}^{b \neq a, j}}{R_{t}^{b \neq a, j}}, \quad t=0,1, \ldots, T
\end{aligned}
$$

\section{References}

Allen, L. R., \& Sparkes, E. C. (2001). The effect of dingo control on sheep and beef cattle in Queensland. Journal of Applied Ecology, 38, 76-87.

Barbier, E. (2001). A note on the economics of biological invasion. Ecological Economics, 39, 197-202.

Barbier, E. (2007). Land conversion, interspecific competition, and bioinvasion in a tropical ecosystem. Journal of Agricultural and Applied Economics, 39, 133-147.

Barbier, E., Knowler, D., Gwatipedza, J., Reichard, S., \& Hodges, A. (2013). Implementing policies to control invasive plant species. BioScience, 63, 132-138.

Batabyal, A. (2007). International aspects of invasive species management: A research agenda. Stochastic Environmental Research and Risk Assessment, 21(6), 717-727.

Bax, N., Williamson, A., Aguero, M., Gonzalez, E., \& Geeves, W. (2003). Marine invasive alien species: A threat to global biodiversity. Marine Policy, 27, 313-323.

Bertignac, M., Campbell, H. F., Hampton, J., \& Hand, A. J. (2000). Maximising resource rent from the western and central tuna fisheries. Marine Resource Economics, 15(3), 151-177.

Bjørndal, T. (1987). Production economics and optimal stock size in a North Atlantic fishery. Scandinavian Journal of Economics, 89, 145-164.

Bjørndal, T. (1988). The optimal management of North Sea herring. Journal of Environmental Economics and Management, 15, 9-29.

Boardman, A., Greenberg, D., Vining, A., \& Weimer, D. (2011). Cost-benefit analysis-concepts and practice (4th ed.). Boston: Pearson Education.

Born, W., Rauschmayer, F., \& Bräuer, I. (2005). Economic evaluation of biological invasions-A survey. Ecological Economics, 55, 321-336.

Brooke, A., Kendrick, D., Meeraus, A., \& Raman, R. (1998). GAMS-A user's guide. Washington DC: GAMS Development Corporation.

Clark, C. (1990). Mathematical bioeconomics. New York: Wiley.

Colautti, R. I., Bailey, S. A., van Overdijk, C. D. A., Amundsen, K., \& MacIsaac, H. J. (2006). Characterised and projected costs of nonindigenous species in Canada. Biological Invasions, 8, 45-59.

Conrad, J. M. (2010). Resource economics (2nd ed.). Cambridge: Cambridge University Press.

Damania, R., Milner-Gulland, E., \& Crookes, D. (2005). A bioeconomic analysis of bushmeat hunting. Proceedings of the Royal Society B, 272, 259-266.

Danielsson, A., Stefansson, G., Baldursson, F. M., \& Thorarinsson, K. (1997). Utilization of the Icelandic cod stock in a multispecies context. Marine Resource Economics, 12, 329-344.

Deevey, E. S. (1947). Life tables for natural populations of animals. Quarterly Review of Biology, 22, $283-314$.

Elofsson, K., Bengtsson, G., \& Gren, I.-M. (2012). Optimal management of invasive species with different reproduction and survival strategies. Natural Resource Modeling, 25, 599-628. 
Finnoff, D., Shogren, J., Leung, B., \& Lodge, D. (2005). The importance of bioeconomic feedback in invasive species management. Ecological Economics, 52, 367-381.

Finnoff, D., Shogren, J., Leung, B., \& Lodge, D. (2007). Take a risk: Preferring prevention over control of biological invaders. Ecological Economics, 62, 216-222.

Fleming, C.-M., \& Alexander, R. R. (2003). Single-species versus multi-species models: The economic implications. Ecological Modelling, 170, 203-211.

Gren, I.-M. (2008). Economics of alien invasive species management-Choices of targets and policies. Boreal Environment Research, 13, 17-32.

Gren, I.-M., Isacs, L., \& Carlsson, M. (2009). Costs of alien invasive species in Sweden. Ambio, 38, $135-141$.

Harvey, C. J., Cox, S. P., Essington, T. E., Hansson, S., \& Kitchell, J. F. (2003). An ecosystem model of food web and fisheries interactions in the Baltic Sea. ICES Journal of Marine Science, 60, 939-950.

Hastings, A., Hall, R. J., \& Taylor, C. M. (2006). A simple approach to optimal control of invasive species. Theoretical Population Biology, 70, 431-435.

Hannesson, R., \& Kennedy, J. (2005). Landing fees versus fish quotas. Land Economics, 81, 518-529.

Heide-Jørgensen, M. P., \& Härkönen, T. (1988). Rebuilding seal stocks in the Kattegat-Skagerrak. Marine Mammals Science, 4, 231-246.

Horan, R. D., \& Lupi, F. (2005). Tradable risk permits to prevent future introductions of invasive alien species into the Great Lakes. Ecological Economics, 52(3), 289-304.

Hulme, P. E. (2009). Trade, transport and trouble: Managing invasive species pathways in an era of globalisation. Journal of Applied Ecology, 46, 10-18.

Jayasuriya, R. T., Jones, R. E., \& van de Ven, R. (2011). A bioeconomic model for determining the optimal response strategies for a new weed incursion. Journal of Bioeconomics, 13(1), 45-72.

Jensen, F., \& Vestergaard, N. (2002). Moral hazard problems in fisheries regulation: The case of illegal landings and discard. Resource and Energy Economics, 24, 281-299.

Jetter, K. M., DiTomaso, J. M., Drake, D. J., Klonsky, K. M., Pitcairn, M. J., \& Sumner, D. A. (2003). Biological control of yellow starthistle. In D. A. Sumner (Ed.), Exotic pests and diseases: Biology and economics for biosecurity (pp. 225-241). Ames: Iowa State University Press.

Järemo, J., \& Bengtsson, G. (2011). On the importance of life history and age structure in biological invasions. Ecological Modelling, 222(3), 485-492.

Karlson, A. M. L., Almqvist, G., Skora, K. E., \& Appelberg, M. (2007). Indications of competition between non-indigenous round goby and native flounder in the Baltic Sea. ICES Journal of Marine Science, 64, 479-486.

Kim, C. S., Lubowski, R., Lewandrowski, J., \& Eiswerth, M. (2006). Prevention or control: Optimal government policies for invasive species management. Agricultural and Resource Economics Review, 35(1), 29-40.

Knowler, D., \& Barbier, E. (2000). The economics of an invading species: A theoretical model and case study application. In C. Perrings, M. Williamson, \& S. Dalmazzone (Eds.), The economics of biological invasions (pp. 70-93). London: Edward Elgar.

Knowler, D., \& Barbier, E. (2005). Importing exotic plants and the risk of invasion: Are market based instruments adequate? Ecological Economics, 52, 341-354.

Knowler, D., Barbier, E., \& Strand, I. (2001). An open access model of fisheries and nutrient enrichment in the Black Sea. Marine Resource Economics, 16(3), 195-217.

Lack, D. (1954). The natural regulation of animal numbers. Oxford: Oxford University Press.

Leung, B., Lodge, D. M., Finnoff, D., Shogren, J. F., Lewis, M. A., \& Lamberti, G. (2002). An ounce of prevention or a pound of cure: Bioeconomic risk analysis of invasive species. Proceedings of the Royal Society of London Series B: Biological Sciences (vol. 269, pp. 2407-2413

Ling, N. (2009). Management of invasive fish. In M. N. Clout \& P. A. Williams (Eds.), Invasive species management (pp. 185-203). London: Oxford University Press.

Lundström, K., Hjerne, O., \& Karlsson, O. (2012). Grey seal (Halichoerus grypus) prey consumption in the Baltic Sea. In: Lundström, K. (2012) Assessment of dietary patterns and prey consumption of marine mammals - grey seals (Halichoerus grypus) in the Baltic Sea. Dissertation, Department of Biological and Environmental Sciences, University of Gothenburg.

MacArthur, R. H., \& Wilson, E. O. (1967). The theory of island biogeography. Princeton: Princeton University Press.

Myers, R. A. (2001). Stock and recruitment: Generalizations about maximum reproductive rate, density dependence, and variability using meta-analytic approaches. ICES Journal of Marine Sciences, 58, 937951. 
Nieminen, E., Lindroos, M., \& Heikinheimo, O. (2012). Optimal bioeconomic multispecies fisheries management: A Baltic Sea case ctudy. Marine Resource Economics, 27(2), 115-136.

Olson, L. (2006). The economics of terrestrial invasive species: A review of the literature. Agricultural and Resource Economics Review, 35(1), 178-194.

Olson, L. J., \& Roy, S. (2005). On prevention and control of an uncertain biological invasion. Review of Agricultural Economics, 27(3), 491-497.

Österblom, H., Hansson, S., Larsson, U., Hjerne, O., Wulff, F., Elmgren, R., \& Folke, C. (2007). Humaninduced trophic cascades and ecological regime shifts in the Baltic Sea. Ecosystems, 10, 877-889.

Perrings, C. (2005). Mitigation and adaptation strategies for the control of biological invasions. Ecological Economics, 52, 315-325.

Pianka, E. R., \& Parker, W. S. (1975). Age-specific reproductive tactics. American Naturalist, 109, $453-464$.

Pimentel, D., Zuniga, D. R., \& Morrison, D. (2005). Update on the environmental and economic costs associated with alien-invasive species in the United States. Ecological Economics, 52(3), 273-288.

Polis, G. A., \& Farley, R. D. (1980). Population biology of a desert scorpion: survivorship, microhabitats, and the evolution of life history strategy. Ecology, 61, 620-629.

Ricker, W. E. (1954). Stock and recruitment. Journal of the Fisheries Research Board of Canada, 11, 559-623.

Sandberg, P. (2006). Variable unit costs in an output-regulated industry: The fishery. Applied Economics, $38,1007-1018$.

Saphores, J.-D., \& Shogren, J. (2005). Managing exotic pests under uncertainty: Optimal control actions and bioeconomic investigations. Ecological Economics, 52, 327-339.

Secord, D. (2003). Biological control of marine invasive species: Cautionary tales and land-based lessons. Biological Invasions, 5, 117-131.

Secretariat of the Convention on Biological Diversity (2001). Review of the efficiency and efficacy of existing legal instruments applicable to invasive alien species. CBD technical series 2. Montreal: Secretariat of the Convention on Biological Diversity.

Skonhoft, A., Vestergaard, N., \& Quaas, M. (2012). Optimal harvest in an age structured model with different fishing selectivity. Environmental and Resource Economics, 51(4), 525-544.

Tahvonen, O. (2009). Economics of harvesting age-structured fish populations. Journal of Environmental and Economic Management, 58(3), 281-299.

Weitzman, M. L. (2002). Landing Fees vs harvest quotas with uncertain fish stocks. Journal of Environmental Economics and Management, 43, 325-338.

Williams, G. C. (1966). Adaptation and natural selection: A critique of some current evolutionary thought. Princeton: Princeton University Press. 